Abstracta Iranica Abstracta Iranica

Revue bibliographique pour le domaine irano-aryen

Volume 30 | 2010

Comptes rendus des publications de 2007

\title{
Knowing the Spirit. Translated and with an introduction by James Winston Morris, State University of New York Press, 2007, 158 p.
}

\section{Mojan Membrado}

\section{(2) OpenEdition}

Journals

Édition électronique

URL : http://journals.openedition.org/abstractairanica/37934

DOI : 10.4000/abstractairanica.37934

ISSN : 1961-960X

Éditeur :

CNRS (UMR 7528 Mondes iraniens et indiens), Éditions de l'IFRI

Édition imprimée

Date de publication : 8 avril 2010

ISSN : 0240-8910

Référence électronique

Mojan Membrado, «Knowing the Spirit. Translated and with an introduction by James Winston Morris, State University of New York Press, 2007, 158 p. », Abstracta Iranica [En ligne], Volume 30 | 2010, document 236, mis en ligne le 08 avril 2010, consulté le 26 septembre 2020. URL : http:// journals.openedition.org/abstractairanica/37934 ; DOI : https://doi.org/10.4000/abstractairanica. 37934

Ce document a été généré automatiquement le 26 septembre 2020.

Tous droits réservés 


\title{
Knowing the Spirit. Translated and with an introduction by James Winston Morris, State University of New York Press, 2007, 158 p.
}

\author{
Mojan Membrado
}

1 Le livre est une traduction de : Nūr-'Alī Elāhī, Ma'refat al-rūh, Tehrān, 1979, 124 p. Il se compose d'une introduction de l'A. ( 4 p.), de huit chapitres (72 p.), et d'une conclusion $(2$ p.) ; le tout précédé d'une préface $(2$ p. $)$ du traducteur J.W. Morris et de son introduction $(25$ p.). Des notes $(28$ p.), une bibliographie $(4$ p.) et un index $(9$ p.) parachèvent le livre.

2 Le texte est rédigé dans un style dense, empruntant le format classique du «commentaire» qui est depuis des siècles la forme standard d'expression philosophique et théologique en terres d'islam. Cette texture inhabituelle au lecteur moderne occidental, recourt simultanément à trois sources de natures différentes: faire argument et produire des preuves et des réfutations rationnelles ('aql), se rapporter à l'intuition spirituelle ( $k$ ašf, šohūd), consolider les résultats obtenus par les deux premières sources grâce aux versets coraniques et à la tradition prophétique/ imâmite (naql).

3 Après avoir expliqué les raisons de la rédaction du livre, l'A. met les jalons d'une discussion centrée sur l'âme humaine, de son Créateur et de sa survie. La structure du livre partant de l'Origine (manba) et se terminant par le Retour (ma'a $\bar{a})$ rappelle la trame des écrits avicenniens, et plus particulièrement celle du traité eschatologique de Mollā Șadrā, al-Hịmat al-'aršiyya (traduction anglaise : J. W. Morris, The Wisdom of the Throne: An Introduction to the Philosophy of Mulla Sadra, Princeton University Press, 1981).

Les chapitres 2 à 6 traitent de la question de l'âme et de sa résurrection. Le réseau argumentatif présenté au long de ces chapitres s'apparente à la tradition métaphysique néo-platonicienne, en particulier à travers les thèses de Mollā Ṣadrā Šīrāzī dont Ostād Elāhī semble avoir une connaissance précise. Le concept de monde imaginal (barzaki) 
et les conceptions eschatologiques du Retour ( $\left.m a^{\iota} \bar{a} d\right)$ exposés par Mollā Șadrā font l'objet d'une reprise critique de l'auteur.

5 Concernant la stratégie d'exposition, dans certains cas les positions philosophiques adverses recensées s'annulent entre elles et dans d'autres, l'A. réfute directement certains arguments. L'effet de vide produit par un tel agencement met en exergue la cohérence des thèses de l'A. lui-même, exposées au chapitre 7, cœur du livre sous le titre «La résurrection selon la doctrine du perfectionnement ». Néanmoins, les thèses présentées dans ce chapitre ne sont pas énoncées en son nom, elles semblent à première vue être une position possible parmi d'autres dans sa recension des doctrines eschatologiques de la tradition théologico-philosophique islamique.

6 La « théorie des vies successives » sans laquelle la justice divine ne serait pas parfaite et qui cautionne la cohérence de l'ensemble de la «doctrine du perfectionnement », est exposée dans ce même chapitre. La notion du corps subtil ou «éthérique » et celle du monde imaginal ou « intermédiaire » (barzaH) y sont également précisées en soulignant leur intérêt dans le processus du perfectionnement de l'âme humaine.

Or l'idée de la pluralité des vies d'une âme unique est souvent assimilée aux théories réincarnationnistes caractéristiques de la pensée pan-indienne; elle a soulevé dans l'islam une réprobation quasi universelle des apologètes. Les traités de réfutation des «transmigrationnistes » les plus anciens remontent aux penseurs mo'tazilites $\mathrm{du} \mathrm{III}^{\mathrm{e}} /$ $\mathrm{IX}^{\mathrm{e}} \mathrm{s}$. relayés par les penseurs shi'ites duodécimains. Les philosophes, ayant une certaine autonomie de l'activité intellectuelle et en relation avec les auteurs grecs traduits en arabe, avaient, comparativement aux apologistes, un intérêt plus grand pour la transmigration (G. Monnot expose le point de vue de Fārābī, Avicenne, Sohrawardī et Mollā Șadrā sur la transmigration dans son Islam et Religions, Paris 1986, pp. 284-290 ; voir aussi Ch. Jambet, Mort et résurrection en islam. L'au-delà selon Mullâ Sadrâ , Albin Michel, 2008).

8 La distinction entre la "théorie des vies successives» et les théories réincarnationnistes se précise dans le dernier chapitre du livre où l'A. approuve un bon nombre des arguments des philosophes musulmans contre la métempsychose.

9 L'originalité de ce livre réside dans le fait que contrairement à d'autres écrits de ce format, au lieu d'éluder cette inadéquation problématique qui existe entre les différentes conceptions de la résurrection de l'âme d'une part et l'idée de la justice divine de l'autre, l'A. la fait ressortir inéluctablement. Puis, après avoir annoncé sa doctrine du perfectionnement, il montre que le principe des vies successives ascendantes n'est pas en contradiction avec le texte coranique et la tradition imâmite.

10 Enfin, les notes du traducteur, tout comme l'introduction, sont d'un intérêt académique certain et contiennent de précieuses informations pour le lecteur non habitué à ce type de texte. Quant aux experts, ils y trouveront de judicieuses mises en perspectives (multiples références aux œuvres d'Ibn 'Arabī entre autres) et des orientations bibliographiques intéressantes. 
INDEX

Thèmes : 9. Philosophie

\section{AUTEURS}

MOJAN MEMBRADO

INaLCO - Paris 